\title{
POLÍTICA DE RESPONSABILIZAÇÃO ESCOLAR (ACCOUNTABILITY SCHOOL) E FORMAÇÃO DE PROFESSOR: CENÁRIOS E ATORES NA AVALIAÇÃO EDUCACIONAL BRASILEIRA
}

\author{
POLÍTICA DE RESPONSABILIDAD ESCOLAR (ACCOUNTABILITY SCHOOL) \\ Y FORMACIÓN DE PROFESORES: ESCENARIOS Y ACTORES EN LA \\ EVALUACIÓN EDUCATIVA BRASILERA
}

\author{
SCHOOL RESPONSIBILITY POLICY (ACCOUNTABILITY SCHOOL) \\ ACADEMIC TEACHER EDUCATION: SCENARIOS AND ACTORS IN THE \\ BRAZILIAN EDUCATION EVALUATIO
}

\author{
Luisa Xavier de OLIVEIRA ${ }^{1}$ \\ Antonia Dalva FRANÇA-CARVALHO ${ }^{2}$ \\ Andrezza Maria Batista do Nascimento TAVARES ${ }^{3}$
}

RESUMO: O instrumento da política de responsabilização são as avaliações em larga escala aplicadas pelos gestores nacionais, estaduais e municipais. O referido estudo objetiva realizar uma discussão sobre a formação de professores e a política de responsabilização escolar (accountability school) desenvolvida no Brasil, observando sua aplicabilidade na política de avaliação educacional. Realizamos uma abordagem bibliográfica e documental, fundamentado no pensamento dos estudiosos: Bonamino e Sousa (2012), Brooke (2006), Horta Neto (2010), Hoffmann (2005), Dias Sobrinho (2003), Pontual (2008), entre outros. O estudo evidenciou que no Brasil há três tipos de política de avaliação educacional; uma diagnóstica que não apresenta implicações a escola e ao currículo; outra de responsabilização branda (low stakes) que acarreta consequências simbólicas junto à escola e seus atores e a terceira classificada como responsabilização forte (high stakes), causando inferências junto a escola e seus atores.

PALAVRAS-CHAVE: Política de responsabilização escolar (accountability school). Avaliação em larga escala. Responsabilização branda (low stakes). Responsabilização forte (high stakes).

RESUMEN: El instrumento de la política de responsabilidad es la evaluación en larga escala aplicada por los gestores nacionales, estatales y municipales. El presente estudio tiene por objetivo realizar una discusión sobre la formación de profesores y la política de responsabilidad en la política de evaluación educativa. Realizamos un abordaje bibliográfico $y$ documental, fundamentado en el pensamiento de los estudiosos: Bonamino e Sousa (2012),

${ }^{1}$ Universidade Federal do Piaú (UFPI), Timon - MA - Brasil. Docente. Doutorado em Educação (UFRJ). ORCID: https://orcid.org/0000-0003-0782-4793. E-mail: luisaxavier77@yahoo.com.br

${ }^{2}$ Universidade Federal do Piauí (UFPI), Teresina - PI - Brasil. Professora Associada II e Docente Permanente do Programa de Pós-Graduação em Educação. Doutorado em Educação (UFC). ORCID: https://orcid.org/00000002-9827-061X. E-mail: adalvac@uol.com.br

${ }^{3}$ Instituto Federal de Educação, Ciência e Tecnologia do Rio Grande do Norte (IFRN), Natal - RN - Brasil. Professora do Programa de Pós-Graduação em Educação Profissional. Doutorado em Educação (UFRN). ORCID: https://orcid.org/0000-0001-6857-7947. E-mail: andrezza.tavares@ifrn.edu.br 
Brooke (2006), Horta Neto (2010), Hoffmann (2005), Dias Sobrinho (2003), Pontual (2008), entre otros. En el estudio quedó evidente que hay tres tipos de política de evaluación educativa en Brasil; una diagnóstica que no presenta implicaciones para la escuela ni para el currículo; otra de responsabilidad blanda (low stakes) que genera consecuencias simbólicas para la escuela y sus actores; y la tercera, clasificada como de responsabilidad fuerte (high stakes) causando inferencias en lo que respecta a la escuela y a sus actores.

PALABRAS CLAVE: Politica de responsabilidad escolar (accountability school). Evaluación en larga escala. Responsabilidad banda (low stakes). Responsabilidad fuerte (high stakes).

ABSTRACT: The accountability policy instrument is the large-scale assessments applied by national, state and municipal managers. This study aims to conduct a discussion on academic teacher education and school accountability policy (accountability school) developed in Brazil, observing its applicability in the educational evaluation policy. We carry out a bibliographic and documentary approach, based on the thinking of scholars: Bonamino and Sousa (2012), Brooke (2006), Horta Neto (2010), Hoffmann (2005), Dias Sobrinho (2003), Pontual (2008) among others. The study showed that in Brazil there are three types of educational evaluation policy; a diagnosis that has no implications for the school and the curriculum; another of bland accountability (low stakes) which has symbolic consequences for the school and its actors and the third classified as strong accountability (high stakes) causing inferences with the school and its actors.

KEYWORDS: School accountability policy (accountability School). Large-scale evaluation. Low accountability (low stakes). Strong accountability (high stakes).

\section{Introdução}

O objetivo do presente artigo é realizar uma discussão sobre a formação de professores e a política de responsabilização escolar (accountability school) desenvolvida no Brasil, observando a sua aplicabilidade na política de avaliação educacional. Tal preocupação se justifica pois é crescente a preocupação com o crescimento e a competitividade dos países em um mundo globalizado tem trazido os sistemas educacionais para o foco. Brooke e Soares (2008, p. 379), afirma que a destinação de maiores recursos destinados à educação "suscita questões relativas à eficácia dos investimentos neste setor e impõe uma aferição cada vez mais detalhada da qualidade da educação oferecida". O termo accountability é oriundo da política e conceitualmente se refere a algumas características, das quais destacamos o controle da ação governamental, ou seja, os governos devem prestar contas, informarem e justificarem suas ações, podendo sofrer sanções caso não ajam de acordo com as regras estabelecidas.

Em um contexto de universalização do ensino fundamental, os debates e as políticas governamentais deslocaram o foco para a expansão das etapas posteriores e para a qualidade, 
apesar da desigualdade e da exclusão ainda se fazerem presentes na realidade brasileira (OLIVEIRA, 2007). Para Oliveira e Adrião (2001, p. 27) "é esta a tendência em todos os países mais desenvolvidos, decorrência do aumento dos requisitos formais de escolarização para o exercício profissional em um processo produtivo [...]”.

No decorrer dos anos de 1990, acentuadamente no período posterior a 1994, a sociedade brasileira viu ganhar centralidade o tema da qualidade do ensino como objeto de regulação federal, cuja viabilidade exigira o aporte de um sistema de informações educacionais conjugado a um sistema nacional de avaliação, considerados ambos os elementos estratégicos da política educacional no país.

Os aspectos relativos à equidade e qualidade desigual ou insuficiente impulsionam os sistemas de avaliação, que, neste sentido, disseminariam informações sobre a educação ofertada para a sociedade e contribuiriam para que houvesse reflexão acerca dos sistemas educacionais a fim de aprimorá-los (PEREIRA, 2019). De acordo com Brooke e Soares (2008, p. 483), a necessidade de se avaliar os sistemas educacionais provém da necessidade de se conhecer a realidade educacional de um país, ou seja, conhecer os dados de "oferta educacional, acesso aos sistemas de ensino, modalidades de ensino, fluxo dos alunos ao longo da trajetória escolar e desempenho escolar".

Para tanto, a necessidade de se obter dados que traduzam a realidade educacional fomenta a implantação de políticas públicas nacionais, estaduais e municipais que utilizam metodologias de avaliação, comparação e controle, na expectativa de que os dados coletados possam subsidiar as discussões dos interessados e dos protagonistas da educação visando um trabalho coletivo em prol da aprendizagem dos alunos (SANTOS; PETOUR, 2019).

A política educacional brasileira exige empenho dos gestores para a melhoria dos indicadores educacionais. A gestão por resultados é uma estratégia recente no âmbito da política educacional, sem perder de vista a garantia da gestão democrática (VIEIRA, 2005). Conforme Moreira Neto (2008, p. 409),

[...] a utilização de índices sintéticos e indicadores relacionados aos programas sociais desenvolvidos têm ganhado espaço e servido de instrumentos para balizar a distribuição de recursos, caminhando para constituírem-se em ferramenta de monitoramento da política pública e em critério de alocação global do gasto público no país.

Há indícios de que os atores escolares já iniciaram a utilização dos resultados das avaliações externas para orientar suas práticas, principalmente explorando os pontos em que os alunos apresentaram mais dificuldade (SANTOS; PETOUR, 2019). Silva (2007), no 
entanto, alerta que esse investimento tem se tornado, por vezes, exacerbado, causando um desequilíbrio, pois conteúdos também importantes são vistos de forma superficial ou omitidos.

Essa é uma discussão que tem pautado os debates escolares e acadêmicos, tendo em vista as avaliações externas normalmente só avaliam os conhecimentos das disciplinas de língua portuguesa e matemática, enquanto as outras disciplinas têm sido relegadas ao segundo plano. Ao que parecem, as interpretações e tomadas de decisão são equivocadas por falta de compreensão e discussão acerca dos objetivos das políticas de avaliação escolar.

\section{Percurso metodológico}

A investigação compreende uma pesquisa tipo exploratória, por meio de abordagem qualitativa, com o uso das técnicas de revisão bibliográfica e de análise documental com a finalidade de buscar um aporte para contextualizar as questões pertinentes à temática. A abordagem qualitativa se aplica ao estudo da história, das relações, das representações, das crenças, das percepções e das opiniões, produtos das interpretações que os humanos fazem a respeito de como vivem, sentem e pensam. Assim, compreendemos que a referida abordagem como filosofia investigativa permite pensar o objeto de estudo a partir de múltiplos aspectos envolvidos na dinâmica dos contextos, tornando possível a compreensão holística dos fenômenos.

Sobre a pesquisa exploratória, Marconi e Lakatos (2010) estabelecem que seu objetivo seja aproximar o pesquisador com o que já foi escrito, filmado ou estudado sobre determinado assunto. Possibilitando com o estudo realizado não uma repetição, mas sim uma reflexão com um novo olhar sobre assuntos já discutidos.

É necessário entender que a "pesquisa bibliográfica constitui o procedimento básico para estudos" (CERVO, 2007, p. 61), e que este é um "meio de formação por excelência", com o intuito de se conhecer os vários olhares sobre o tema, em livros, periódicos, dissertações, monografias, dentre outros mais.

A pesquisa tipo exploratória aproxima o pesquisador da problemática de pesquisa por meio do aprimoramento das ideias. O designer deste tipo de investigação é flexível, de modo que múltiplos aspectos do objeto possam ser compreendidos e analisados, inclusive, aqueles que são desvelados pelo pesquisador em meio a travessia da experiência.

Para explorar a temática da avaliação em larga escala e as políticas de responsabilização escolar, inicialmente recorremos à diversidade de autores utilizados em 
tempo e localização que permitiu vários olhares sobre o tema, assim também como a articulação das idéias. Utilizamos também, a pesquisa documental, como o próprio nome sugere, é o estudo de documentos. Para esse estudo analisamos os documentos legais que norteiam a avaliação educacional nas seguintes leis: a Constituição Federal de 1988 e a Lei de Diretrizes e Bases (LDB) de $n^{\circ}$ 9.394/96 com o intuito de que seja articulada uma reflexão em torno da Avaliação Educacional adotada no Brasil, quanto a sua normatização e qualidade, bem como na contribuição da formação profissional e das questões educacionais contemporâneas.

\section{Avaliação em larga escala e as políticas de responsabilização escolar}

A implantação das avaliações externas em larga escala, trouxe novamente para o centro dos debates o termo "avaliar", que a partir do século XIX até a atualidade se mantêm como um tema amplo, complexo, frequente, necessário e suscetível de acaloradas discussões e interpretações de críticos acirrados e defensores eloquentes. Dias Sobrinho (2003, p. 13) expõe que "a avaliação adquiriu dimensões de enorme importância na agenda política dos governos, organismos e agências dedicadas à estruturação e à gestão do setor público e particularmente da Educação". Colaborando ainda com o pensamento anteriormente expresso, o mesmo autor, pontua que "é na educação que a avaliação encontrou o seu espaço privilegiado, não só como prática política e pedagógica, produzindo efeitos dentro e fora do âmbito propriamente educacional, mas também como importante campo de estudo" (op. cit., p. 15).

Iniciada com um princípio de realização de aptidões orais, que embora não declaradas já realizavam menção às classificações, evoluindo para uma subsequente de testes escritos, praticada desde seu advento, com um significativo nível de sistematização e organização. A partir do século XIX, a avaliação inicia uma trajetória que permite a roupagem atual como, por exemplo, a definição como uma disciplina e um novo campo do saber no currículo oficial, mas que ainda necessita de estudos e pesquisas aprofundados para que possa alcançar um maior nível de afirmação (DIAS SOBRINHO, 2003).

No campo educativo da avaliação, o grande impulso foi dado por Tyler (1950) com a proposta de um "Ensino por Objetivos", propondo a construção da aprendizagem que se iniciou após a Revolução Francesa que colocou as grandes massas populacionais dentro dos ambientes de ensino trazendo várias alterações a dinâmica vigente dos Estados Unidos que se alastraram pelos demais países. 
Lançando o pensamento sobre a eficiência dos sistemas de ensino mundiais, ainda que, em passos lentos, pois, o reconhecimento efetivo no Brasil e utilização da nomenclatura avaliação só ocorreram de modo efetivo com a promulgação da LDB 9.394/96, que trouxe em sua pauta questões como currículo, formação de professores e avaliação dos alunos que até então, não havia um espaço garantido. As legislações educacionais anteriores de LDB 4.024 de 1961, usava a definição de "Sistemas de Exames" e a de LDB 5.692 de 1972, se referia a “Aferição do Aproveitamento Escolar".

A compreensão teórica conquistada na caminhada de percalços da avaliação é bastante positiva e as inovações pedagógicas inseridas pela Escola Nova contribuíram de modo relevante, pelo fato de diversos estudiosos defenderem a implantação de novas metodologias no processo de ensino-aprendizagem alcançando a definição contemporânea de processual, não pontual, dinâmica, inclusiva, dialógica, sistemática, democrática, multidimensional e caracterizada em três tipos: diagnóstica (início), formativa (durante) e somativa (final do processo), (DIAS SOBRINHO, 2003; HOFMANN, 2005). Utilizando das argumentações de Horta Neto (2010, p. 89) que "considera que todos os tipos de avaliação são importantes e que tratam de responder a diferentes necessidades dos sistemas educativos e da vida em sociedade; elas fazem partem do dia a dia do processo educativo".

Nesse cenário, as avaliações externas de larga escala ganharam grandes proporções na sociedade, buscando nutri-la do que poderíamos chamar de "prestação de contas", por intermédio dos resultados obtidos na co-responsabilização de seus agentes (professores, gestores, diretores e alunos) e pelos índices alcançados sejam eles, positivos, ou negativos criando instrumentos meditativos objetivando uma melhora efetiva da "qualidade do ensino". Em Brooke e Cunha (2011, p. 22) vamos encontrar o seguinte esclarecimento "A accountability no contexto educacional significa acima de tudo associação entre resultados de aprendizagem e consequências para o distrito educacional, a escola, os professores e os alunos".

No Brasil, a primeira política de responsabilização escolar a ser implantada foi o Programa de Expansão e Melhoria do Ensino no Meio Rural do Nordeste (EDURURAL) voltada aos Estados do Pernambuco, Piauí e Ceará que destacaram o nível de desempenho real encontrado em relação à sociedade brasileira. Ampliada posteriormente para todo o país com a criação do Sistema de Avaliação do Ensino de Primeiro Grau (SAEP).

Na década de 1990, ocorre à substituição do SAEP, pelo Sistema de Avaliação da Educação Básica (SAEB), vigente na atualidade que se configura como um marco no cenário nacional. Destinado as áreas de Língua Portuguesa e Matemática, as provas aplicadas de 
forma censitária nas etapas finais do Ensino Fundamental e médio $\left(5^{\circ}, 9^{\circ}\right.$ e $3^{\circ}$ Anos) respectivamente, o que permite o acompanhamento evolutivo ao longo dos anos, pelo fato de ter sido adotado em 1995, através do uso da Teoria de Resposta ao Item ${ }^{4}$ (TRI) que avalia o desenvolvimento das habilidades por meio da padronização de testes.

A articulação dos ministérios da educação e secretárias estaduais foram o que impulsionaram a implantação e reestruturação gradativa ao longo dos anos ocupando a configuração atual de um mecanismo detalhado da qualidade, funcionamento e gerenciamento da educação que através da aplicação de testes em grandes proporções e aplicação de questionários, obtêm um diagnóstico da qualidade de educação e subsidiam na implantação de políticas públicas educacionais com objetivo de melhorar e aprimorar a situação em que a prática do saber se encontra. Fazem parte dessas avaliações: a Avaliação Nacional do Rendimento Escolar (ANRESC) popularmente conhecida como Prova Brasil, Avaliação Nacional da Alfabetização (ANA), Avaliação Nacional da Educação Básica (ANEB) que englobam obrigatoriamente a rede pública, se destinam as redes públicas e particulares averiguando os níveis de alfabetização e letramento, possui uma dinâmica amostral e por sorteio respectivamente. As junções das médias com os dados do Censo Escolar compõem o Índice de Desenvolvimento da Educação Básica (IDEB) e estabelecem metas vindouras para as redes de ensino.

Outra criação é o Exame Nacional do Ensino Médio (ENEM), que de forma restritiva ao longo do seu caminhar vem assumindo as características certificatórias, pois é requisito e critério para o ingresso no Ensino Superior público, após concluir a Educação Básica, mas embora muitas universidades tenham aderido ao mesmo, ainda não é geral uma cobertura legal por parte de todos os estados, pois algumas instituições realizam seus próprios processos avaliativos/vestibulares.

Como uma forma de criar mecanismos mais detalhados de funcionamento e gerenciamento da qualidade da educação em seus próprios Estados, a partir da década de 1990, diversos Estados instituíram seus próprios sistemas avaliativos. São exemplos: o Sistema Permanente de Avaliação do Estado do Ceará (SPAECE) em 1992, o Sistema de Avaliação do Rendimento do Estado de São Paulo (SARESP) em 1996, O Sistema Mineiro de

\footnotetext{
${ }^{4}$ Se refere a uma metodologia de avaliação elaborada com base nas matrizes de referências que é formado por um conjunto de descritores, previamente estabelecidas para determinadas disciplinas avaliativas,que objetiva que em determinados níveis o aluno tenha desenvolvido habilidades cognitivas, evitado assim, chutes. Um dos vários exemplos que utiliza essa estratégia é o Exame Nacional do Ensino Médio (ENEM) e os Estados com seus sistemas próprios de avaliação com por exemplo, o Sistema Permanente de Avaliação do Estado do Ceará (SPAECE) e o Sistema de Avaliação Educacional do Piauí (SAEPI) (BROOKE, 2006); (DIAS SOBRINHO, 2003).
} 
Avaliação da Educação Pública (SIMAVE) em 2000, O Programa Nova Escola do Rio de Janeiro no ano de 2000 que foi substituído logo em seguida, pelo Sistema de Avaliação do Estado do Rio de Janeiro (SAERJ), e o Sistema de Avaliação do Estado do Piaú́ (SAEPI) que sua criação é bem mais recente referente ao ano de 2011(CERDEIRA; ALMEIDA; COSTA, 2014). Brooke e Cunha (2011, p. 18) alegam que:

\begin{abstract}
Muitas vezes, essas novas políticas envolvem a identificação e classificação das escolas com base nos resultados do $5^{\circ}$ e $9^{\circ}$ Ano do Ensino Fundamental e $3^{\circ}$ Ano do Ensino Médio, que são as informações disponibilizadas pela maioria dos sistemas estaduais de avaliação que seguem o padrão do Sistema da Educação Básica (SAEB).
\end{abstract}

Os resultados das avaliações externas são utilizados como instrumentos de gestão educacional, mecanismo de informatização dos níveis de aprendizagem dos alunos ao público, definição de estratégias de formação continuada, alocação de recursos, incentivo de bônus salariais, certificação de alunos e escolas. No Brasil, diferentemente dos países americanos não há relações entre os testes e o futuro dos alunos, como também não ocorre à inclusão de familiares o que pode acarretar o uso de accountability fragmentadas/parciais, (BROOKE; CUNHA, 2011).

Brooke (2006) chama a atenção para o estreitamento do currículo, possibilidade da centralização nos conteúdos das disciplinas que são avaliadas (português e matemática) em detrimento às demais um segundo plano e práticas fraudulentas que alterem a realidade concreta em prol do recebimento de recursos (MEDEIROS; AGUIAR, 2018).

Corroborando com esse pensamento Horta Neto (2010, p. 90) expõe que "os dados e as percepções sobre a realidade nem sempre captam a realidade. Eles são aproximações dessa realidade". Ainda segundo o autor:

\footnotetext{
É importante salientar que, mesmo tendo seus limites, a avaliação é capaz de fornecer informações para a tomada de decisões para a implantação de políticas públicas, e nesse sentido, é muito melhor do que um vôo cego, no qual não existem dados em que os formuladores de políticas possam se embasar (op.cit. p. 90).
}

A preocupação com a qualidade da Educação Básica está no cerne dos programas subnacionais de avaliação. Apesar de usarem instrumentos descendentes do SAEB, que são fundamentalmente de monitoramento e não de diagnóstico, todos têm como objetivo explícito fornecer feedback aos professores de sala de aula e ajudar na busca de soluções para superar as dificuldades de aprendizagem dos alunos (BROOKE; CUNHA, 2011). 
No Brasil, Bonamino (2012) caracteriza três tipos de avaliação em larga escala. A diagnóstica que não atribui nenhum tipo de consequência à escola e ao currículo escolar que é chamada de primeira geração; às de responsabilização branda (low stakes) que acarretam consequências simbólicas denominadas de segunda geração e a terceira que funciona como uma responsabilização forte ou responsabilização forte (high stakes) que traz consequências materiais. As duas últimas citadas possuem mecanismos de remuneração de acordo com as normas estabelecidas e metas obtidas previamente, bem como promovem interferências nos espaços escolares. Seu funcionamento ocorre em torno da visão de aperfeiçoamento pelo fato de ser uma prestação de contas, pressão por melhores resultados, apoiada na definição de metas junto ao Índice de Desenvolvimento da Educação Básica (IDEB).

Essas associações e consequências se articulam a bonificação salarial dos profissionais da educação e definem novos contextos desde a sua implantação por acrescentar diálogos e pesquisas sobre o tema evidenciando o grande desafio de educadores que é a oferta de uma educação de qualidade, em proporções acima da divulgação dos resultados externos, colocando assim, vários agentes no centro da contenda, visto ora como vilões, ora como heróis.

Os discursos dos estudiosos lado, estão oscilam entre dois extremos: de um os críticos que buscam investigar os reflexos da reforma política na organização da educação e do ensino; de outro, os defensores da implementação e aprimoramento, como meio de responsabilização dos profissionais e suposta melhoria da qualidade educacional (SOARES; ALVES, 2013, p. 449).

Para Pontual (2008) tais investidas em larga escala ganharam proporções com o Programa Internacional de Avaliação de Estudantes (PISA) que oferece uma medida padronizada de qualidade realizando agregação entre desempenho de alunos e bonificação docente. "A remuneração de professores na maioria dos sistemas de ensino é única para todos os profissionais, ofertando uma base salarial que varia com base em dois critérios: tempo de serviço e titulações obtidas" (Ibidem, p. 05).

Entre seus pós e contras, há defensores favoráveis e críticos severos. O que está em pauta nessas discussões de avaliações em larga escala é qualidade do ensino ofertado nos países que adotaram no seu interior tais estratégias (PEREIRA, 2019). Por se tratar de uma área que naturalmente suscita gigantescos investimentos. Brooke (2006) destaca que há necessidade de um maior nível de compreensão e aprofundamento teórico sobre a pauta que se viabiliza por meio de pesquisas para que possa criar conexões entre sistemas e responsabilizações mais consistentes. 


\section{Formação profissional docente e a políticas de responsabilização escolar}

Avaliar sucinta heterogeneidade e a necessidade de profissionais aptos para tal exercício que devem prover de divergentes métodos e concepções teóricas para não realizar interpretações errôneas acerca dos resultados que são divulgados pelas agências de avaliação. Para que não ocorram discrepâncias e danos, se fazem válidas a construção de diálogos coletivos acerca do que é cobrado pelos sistemas de avaliação, caso contrário, os investimentos em formações, oficinas pedagógicas se tornam inócuas, caso não exista um currículo comum (BROOKE; CUNHA, 2011).

Para efetivação de uma educação de qualidade capaz de incluir é de fundamental importância a junção de inúmeras e diversificadas variáveis a exemplo, da implantação de políticas públicas capazes de serem postas e efetivadas na prática, uma compreensão real e aprofundada da educação que está sendo ofertada a grande massa populacional, compromisso de todos os sujeitos que trabalham com educação. O Plano Nacional de Educação (PNE) nas metas dezesseis, dezessete e dezoito expõe sobre qualidade relacionada à formação profissional, respectivamente:

Formar, em nível de pós-graduação, 50\% (cinquenta por cento) dos professores da educação básica, até o último ano de vigência deste PNE, e garantir a todos (as) os (as) profissionais da educação básica formação continuada em sua área de atuação, considerando as necessidades, demandas e contextualizações dos sistemas de ensino.

Valorizar os (as) profissionais do magistério das redes públicas de educação básica de forma a equiparar seu rendimento médio ao dos (as) demais profissionais com escolaridade equivalente, até o final do sexto ano de vigência deste PNE.Assegurar, no prazo de 2 (dois) anos, a existência de planos de Carreira para os (as) profissionais da educação básica e superior pública de todos os sistemas de ensino e, para o plano de Carreira dos (as) profissionais da educação básica pública, tomar como referência o piso salarial nacional profissional, definido em lei federal, nos termos do inciso VIII do art. 206 da Constituição Federal (BRASIL, 2014, p. 51).

A conquista de espaço, em documentos legais, é um passo positivo em direção a eficácia escola, já que o professor/educador tem papel fundamental na qualidade da educação de todo e qualquer país. Partimos da assertiva que uma singela remuneração aos profissionais das escolas que se destacam não é capaz de solucionar as lacunas e falhas existentes em um curto espaço de tempo.

As políticas de bonificação salariais podem criar problemas gaming ${ }^{5}$, manipulações as regras realizadas pelas escolas como: não aplicação das

${ }^{5}$ Utilização de práticas fraudulentas em prol de bons resultados (BROOKE, 2006).

RIAEE - Revista Ibero-Americana de Estudos em Educação, Araraquara, v. 15, n. 4, p. 2049-2065, out./dez. 2020. e-ISSN: $1982-5587$. 
avaliações a alunos com menores desempenhos estudantis, menor preocupação com as séries que não são abarcadas pelas avaliações externas, transferências brancas de alunos com baixo desempenho para outras instituições (BROOKE; CUNHA, 2011).

Como essas práticas envolvem uma série de sujeitos e processos para sua efetivação podem alternar-se de motivador á desmotivador, a curtos e rápidos espaços de tempo, causando sentimentos de pressão e desvalorização ou de preparação elevada para alcançar bons índices, deixando a formação integral dos alunos que são o centro do processo educativo em segundo plano, desvalorizando suas discrepantes realidades.

Vieira (2007, p. 58) conceitua que "a escola não se reduz a um mero reverso de políticas, mas antes se configura como espaço de reconstrução e de inovação, oferecendo elementos para a formulação de novas políticas". Que ao serem concretizadas na prática se transformam em gestão. Para Freitas, (2013, p. 14) "A escola não é um local ingênuo sob um sistema social qualquer, dela espera-se que cumpra uma determinada função”.

Uma vez que o espaço escolar se insere na sociedade, a avaliação e o currículo escolar trazem traços da mesma (MEDEIROS; AGUIAR, 2018). Diante disso, o conhecimento e a reflexão sobre as interfaces com o currículo são relevantes, tendo em vista que as diversas políticas implantadas ao longo da história refletem/espelham em determinadas fases vividas pela sociedade. Apresentando-se em uma encruzilhada de um lado a está a defesa de uma educação democrática e cidadã, e de outro um ensino voltado ao mercado de trabalho, desde a década de 1990 o estado passou a dar ênfase em políticas centrando-se na regulação e avaliação (MENEGÃO, 2015).

É correto afirmar que o termo "qualidade" comporta inúmeras polissemias, o que pode gerar entendimentos errôneos e equivocados prejudicando a efetivação de uma educação integral de qualidade que se constitui em um dos vários direitos fundamentais do ser humano, ao centra-se em ações objetivando bons resultados nas avaliações externas, deflagrando um processo que deve ser extenso, complexo e equitativo para potencializa e induzir várias outras habilidades.

Ao debater sobre avaliação e qualidade é necessário colocar no centro das atenções alguns pontos significativos pelo fato de serem válidos e inacabados. Nesse sentido não podemos deixar de realizar menção ao currículo escolar oficial, pois no mesmo é explícito as áreas do conhecimento que deverão ser trabalhadas desenvolvendo habilidades nos estudantes. Menegão (2015, p. 56) discorre que: 
O currículo pode ser entendido como um significativo instrumento utilizado nos mais diferentes tempos e sociedades, tanto para desenvolver processos de conservação, como de transformação e renovação dos conhecimentos historicamente acumulados, e assim socializar os alunos segundo valores tidos como desejáveis.

Mediante as colocações nos posicionamos que nada na sociedade é amplamente neutro, pois há um jogo de poder que cerca e norteia a sociedade explicitamente e implicitamente, além da subjetividade inerente a todos os sujeitos. Sobre currículo chamamos para participar da discussão Gimeno (1992 apud PACHÊCO, 2005, p. 25) ao expor que "o currículo define um território prático sobre o qual se pode intervir, investigar, mas, primeiro de tudo, no qual é preciso intervir”. Não existe neutralidade, como define um dos maiores estudiosos e teóricos da educação Freire a mesma é um ato político, que envolve um jogo de forças na qual as classes dominantes impõem o seu pensar sobre os grupos menos favorecidos (MEDEIROS; AGUIAR, 2018).

Nesse panorama, os professores não são somente meros executores de ações mecanizadas, inserem na sua forma de trabalhar as suas percepções sobre o mundo que os rodeia com sua ampla totalidade, estabelecendo relações sociais, políticas, sociais que se relaciona com sua forma particular de ser, sua formação e seus contextos diários de vida. Sustentando-se no ponderar de Luck (2009, p. 116) "uma escola é uma organização social construída pelas interações das pessoas que dela fazem parte, orientadas pelos seus valores, crenças, mitos e rituais".

Na maioria das vezes, as ações são determinadas de forma verticalizada, de cima para baixo, sem considerar as especificidades reais. Ao considerar apenas o currículo oficial, simplifica a capacidade de aptidões críticas bem formuladas e tal processo não pode reduzirse a classificar ou não os desempenhos dos sujeitos que o realizam modulando o próprio acesso ao conteúdo.

Compartilhamos do pensar de Menegão (2015, p. 33) quando afirma que "a educação é decisiva para a formação integral humanística e científica de sujeitos autônomos, críticos, criativos e protagonistas da cidadania ativa". Reafirmando esse ponto de vista, Libâneo (2006, p. 97) discorre que "as escolas têm uma tarefa muito clara que é a transmissão e a construção da cultura, da ciência, da arte, preparar os alunos para o trabalho, para a cidadania, para a vida cultural, para a vida moral".

Ao longo dos séculos alcançamos conquistas como um maior número de sujeitos concludentes da educação básica, mas não concretizamos o grande desafio de ofertar um ensino de qualidade e equidade. "Os obstáculos à democratização do ensino foram 
transferindo-se de acesso para a permanência de todos os estudantes na escola" (BORGES, 2016, p. 98). Ao que se refere à educação como direito é perceptível que alcançamos em termos legais, basta para isso realizarmos uma retrospectiva na história nacional, no entanto na efetivação real das ações são gritantes e alarmantes os desafios e disparidades evidenciados.

\section{Considerações finais}

Educação e avaliação sempre andaram de mãos dadas. Tal fato, certamente nada estranho a todos aqueles que frequentaram por anos as unidades escolares, hoje, no contexto crescente do uso de indicadores econômicos, educacionais e estatísticos, se tornam algo com finalidade bem diferente dos antigos testes escolares para avaliar, reprovar ou aprovar, significativa parcela da população discente. Se anteriormente, o objetivo era eliminar de forma preliminar os alunos considerados inaptos para a escolarização, especialmente nas séries iniciais do ensino fundamental, atualmente, o enfoque avaliativo constituiu-se de outros objetivos mais definidos, sendo principalmente, pautados em medir e escalonar os resultados da aprendizagem escolar visando mensurar a qualidade do ensino oferecido (OLIVEIRA, 2007).

A potencialidade de gerar discussões fez do assunto da qualidade de ensino, atrelado à avaliação em larga escala, elemento com ênfases teóricas completamente divergentes. São inúmeros os autores que discutem o sistema de avaliação em larga escala baseado em testes padronizados, dentre eles, Martins (2001) que considera a realização de avaliação externa sobre os resultados obtidos pelas escolas, um importante indicador para que os gestores dos sistemas de ensino possam corrigir problemas e reorientar decisões e percursos institucionais, porém, a mesma autora enfatiza que as metodologias que desconsideram a diversidade cultural existente no âmbito escolar não captam a efetiva dinâmica das unidades escolares, tendo como base apenas os resultados finais obtidos por testes padronizados.

$\mathrm{Na}$ outra extremidade, porém, há aqueles que acreditam ser possível utilizá-la como instrumento significativo para a melhoria dos padrões de qualidade e implementação de novas políticas públicas. Souza (2005) defende que a avaliação em larga escala não se destina a reprovar ninguém, mas a fornecer informações aos gestores educacionais e ao público, sobre o desempenho do sistema escolar, oportunizando as escolas, as regiões, os municípios ou Estados demonstrando no que precisam melhorar quanto aos seus resultados, bem como o que é necessário fazer para promover essa melhoria. 
A favor ou não, a verdade é que, as avaliações assumem uma posição estratégica nas agendas governamentais, pois se acredita que elas contribuíram para a qualidade da administração pública e promove sustentabilidade à reforma. Isto porque as atividades avaliativas permitem controlar os resultados obtidos, responsabilizar os prestadores de serviço pelos resultados, bem como transmiti a imagem de um Estado que se preocupa e respeita os interesses dos cidadãos (CLÍMACO, 2005).

Para tanto, a avaliação passou a ser uma atividade presente em todos os setores sociais, tornando-se o eixo norteador do processo regulatório estatal. Todavia, foi no campo educacional que as avaliações ganharam proeminência, tendo em vista que o conhecimento passou a ser elemento chave para o desenvolvimento da economia, através das mudanças tecnológicas, das descobertas científicas e inovações.

Avaliação como parte de um processo de coleta e análise de informações para tomada de decisões, torna-se um instrumento ímpar na educação, uma vez que a avaliação de sistemas pode permitir que gestores atuem mediante informações básicas sobre a rede de ensino. Políticas de avaliação e de responsabilização escolar - accountability school - têm sido implementadas em diversos países com o intuito de tornar públicas as informações sobre o desempenho dos alunos e, consequentemente, do trabalho dos atores envolvidos no cotidiano escolar, sendo estes considerados co-responsáveis pelo desempenho alcançado pela instituição escolar.

Deste modo, a construção de uma cultura avaliativa pode ser capaz de oferecer subsídios para tomada de decisões na perspectiva da qualidade. O desafio ainda é a apropriação dos resultados obtidos pelos atores da escola, bem como a utilização dos mesmos com o objetivo de orientar as atividades de ensino.

As formas como as avaliações são introduzidas nas escolas e as formas de divulgação dos resultados podem influenciar nas discussões e práticas dos atores em função de suas percepções. Com efeito, as reações diferentes diante do desconhecimento e do entendimento superficial, podem produzir distanciamento, resistência, submissão e passividade, mas também um esforço para compreensão e utilização dos resultados por parte dos sujeitos escolares.

\section{REFERÊNCIAS}

BONAMINO, A. SOUSA, Z. S. Três gerações de avaliação da educação básica no brasil: Interfaces com o currículo da/na escola. Educação e Pesquisa, São Paulo, v. 38, n. 2, p. 378388, abr./maio 2012. 
BORGES, H. Conheça os bilionários convidados para reformar a educação brasileira de acordo com sua ideologia. The Intercept Brasil, 4 nov. 2016. Disponível em:

BRASIL. Constituição da República Federativa do Brasil de 1998. Disponível em: https://www2.senado.leg.br/bdsf/bitstream/handle/id/518231/CF88_Livro_EC91_2016.pdf?se quence $=1$ ? concurso $=\mathrm{CFS} \% 202 \% 202018$. Acesso em: $10 \mathrm{fev} .2020$.

BRASIL. Lei n. 10.172, de 9 de janeiro de 2001. Aprova o Plano Nacional de Educação e dá outras providências. Diário Oficial da União, Brasília, DF, 10 jan. 2001. Disponível em: http://www.planalto.gov.br/ccivil_03/leis/leis_2001/110172.htm. Acesso em: 12 fev. 2020.

BRASIL. Lei n. 13.005, de 25 de junho de 2014. Aprova o Plano Nacional de Educação e dá outras providências. Diário Oficial da União, Brasília, DF, 26 jun. 2014. Disponível em: http://pne.mec.gov.br/18-planos-subnacionais-de-educacao/543-plano-nacional-de-educacaolei-n-13-005-2014. Acesso em: 12 fev. 2020.

BRASIL. Lei n. 9.394/96, de 20 de dezembro de 1996. Estabelece as diretrizes e bases da educação nacional. Diário Oficial da União, Brasília, DF, 23 dez. 1996. Disponível em: http://www.planalto.gov.br/ccivil_03/leis/L9394.htm. Acesso em: 15 fev.2020.

BROOKE, N. CUNHA, M. A. A. A avaliação externa como instrumento de gestão educacional dos estados. Estudos e pesquisas educacionais, 2011. Disponível em: http://www.educadores.diaadia.pr.gov.br/arquivos/File/pdf/avaliacao_externa_fvc.pdf. Acesso em: 2 jan. 2019.

BROOKE, N. O futuro das políticas de responsabilização no Brasil. Cadernos de Pesquisa, v. 36, n. 128 , p. 377-401, maio/ago. 2006.

BROOKE, N.; SOARES, J. F (Org). Pesquisa em eficácia escolar: origens e trajetórias. Belo Horizonte: UFMG, 2008.

CERDEIRA, D. G. S.; ALMEIDA, A. B.; COSTA, M. Indicadores e Avaliação Educacional: Percepções e Reações a Políticas de Responsabilização. Avaliação: Estudo em Avaliação Educacional, São Paulo, v. 25, n. 57, p. 198-225, jan./abr. 2014.

CERVO, A. L. Metodologia científica. Trad. Amado Luiza Cervo, Pedro Alcino Bervian e Roberto da Silva. 6. ed. São Paulo: Pearson Prentenci Hall, 2007.

CLIMACO, M. C. Avaliação de sistemas em educação. Lisboa: Universidade Aberta, 2005.

DIAS SOBRINHO, J. Avaliação políticas educacionais e reformas da educação superior. São Paulo: Cortez, 2003.

FREITAS, L. C. Políticas de responsabilização: entre a falta de evidência e a ética. Cadernos de Pesquisa, v. 43 n. 148 p. 348-365, jan./abr. 2013.

HOFMANN, J. Avaliação: mito e desafio - uma perspectiva construtivista. 35. ed. Porto Alegre: Mediação, 2005. 
HORTA NETO, J. L. Avaliação externa de escolas e sistemas: questões presente no debate sobre o tema. Revista Brasileira de Estudos Pedagógicos, Brasília, v. 91, n. 227, p. 84-101, jan./abr. 2010.

https://theintercept.com/2016/11/04/conheca-os-bilionarios-convidados-para-reformar-aeducacao-brasileira-de-acordo-com-sua-ideologia/. Acesso em: 12 fev. 2020.

LUCK, H. Dimensões da gestão escolar e suas competências. Curitiba: Positivo, 2009.

MARCONI, M. A.; LAKATOS, E. M. Fundamentos de metodologia científica. São Paulo: Editora Atlas, 2010.

MARTINS, A. M. A descentralização como eixo das reformas do ensino: uma discussão da literatura. Educação \& Sociedade, n. 77, ano XXII, p. 28-48, dez. 2001.

MEDEIROS; E. A.; AGUIAR; A. L. O. Formação Inicial de Professores da educação básica em licenciaturas de universidades públicas no Rio Grande do Norte: estudo de currículos e suas matrizes curriculares. Revista Ibero-Americana de Estudos em Educação, Araraquara, v. 13, n. 3, 2018 .

MENEGÃO, R. C. S. G. Impactos da avaliação externa no currículo escolar: percepções de professores e gestores. 2015. 272 f. Tese (Doutorado em Educação) - Universidade Estadual de Campinas, 2015.

MOREIRA NETO, J. G. Sistemas de indicadores educacionais no acompanhamento e avaliação de políticas públicas. Revista Estudos em Avaliação Educacional, v. 19, n. 41, set./dez. 2008.

OLIVEIRA, R. P. O financiamento da educação. In: OLIVEIRA, R. P.; ADRIÃO, T. (Org.). Gestão, financiamento e direito à educação: análise da constituição federal e da LDB. 3. ed. São Paulo: Xamã, 2007.

OLIVEIRA, R. P.; ADRIÃO, T. (Org.). Gestão, financiamento e direito à educação. São Paulo, 2001.

PACHÊCO, J. A. Escritos curriculares. São Paulo: Cortez, 2005.

PEREIRA, R. S. Proposições da OCDE para América Latina: o Pisa como instrumento de padronização da educação. Revista Ibero-Americana de Estudos em Educação, Araraquara, v. 14, n. esp. 3, 2019.

PONTUAL, T. C. Remuneração por mérito, desafio para a educação. Fundação Lemann, 2008.

SANTOS, F. A.; PETOUR, M. T. F. Internacionalização dos sistemas de avaliação: evidências de Brasil e Chile. Revista Ibero-Americana de Estudos em Educação, Araraquara, v. 14, n. esp. 3, 2019. 
SILVA, M. J. A. O sistema mineiro de avaliação da educação pública: impactos na escola fundamental de Uberlândia. Revista Iberoamericana sobre Calidad, Eficacia y Cambio en Educación, v. 5, 2007.

SOARES, M. T. G; ALVES. J. F. Contexto escolar e indicadores educacionais: condições desiguais para a efetivação de uma política de avaliação educacional. Educação e Pesquisa, São Paulo, v. 39, n. 1, p. 177-194, jan./mar. 2013.

SOUZA, A. M. (Org.). Dimensões da avaliação educacional. Petrópolis: Vozes, 2005.

VIEIRA, S. L. Políticas e gestão da Educação Básica: Revisitando conceitos simples.

RBPAE, Rio Grande do Norte, v. 23, n. 1, p. 53-69, jan./abr. 2007.

VIEIRA. S. L. Educação e gestão: extraindo significados da base legal. In: SECRETARIA DA EDUCAÇÃO BÁSICA DO CEARÁ. Novos paradigmas de gestão escolar. Fortaleza: SEDUC, 2005a. p. 7-26.

\section{Como referenciar este artigo}

OliveirA, L. X. de; CARVAlho, A. D. F.; TAVARES; A. M. B. do N. Política de responsabilização escolar (accountability school) e formação de professor: cenários e atores na avaliação educacional brasileira. Revista Ibero-Americana de Estudos em Educação, Araraquara, v. 15, n. 4, p. 2049-2065, out./dez. 2020. e-ISSN: 1982-5587. DOI: https://doi.org/10.21723/riaee.v15i4.13887

Submetido em: 16/01/2020

Revisões requeridas em: 25/04/2020

Aprovado em: 30/05/2020

Publicado em: $30 / 08 / 2020$ 